\title{
Carlos Vidal PRAdo, El derecho a la educación en España. Bases constitucionales para el acuerdo y cuestiones controvertidas, co- lección Debates Constitucionales, Marcial Pons y Fundación Gi- ménez Abad, 2017, 144p, ISBN:9788491234319.
}

\author{
doi: http://dx.doi.org/10.18543/ed-65(2)-2017pp437-439
}

Es de sobra conocido el hecho de que la elaboración del art. 27 de la Constitución constituyó una de las pruebas más difíciles de superar para lograr el consenso necesario en el proceso constituyente, hasta el punto de que el modo de reconocimiento de los derechos educativos y la libertad de enseñanza motivó que dejara la Ponencia Constitucional el representante del entonces primer partido de la oposición, Sr. Peces-Barba, comprometiéndose de esta manera el éxito de la tarea constituyente.

Asimismo, es sintomático que gran parte de las leyes de desarrollo del artículo 27 hayan sido impugnadas ante el Tribunal Constitucional. No sólo eso, sino que aquellas leyes que no han sido impugnadas ante el TC por los sujetos legitimados ex art. 162 CE no por ello han estado exentas de polémica política o de oposición jurídica, como sucedió en el caso de la Ley orgánica de Educación y la polémica (que llegó al Tribunal Supremo y al Tribunal Constitucional) acerca de la materia «Educación para la ciudadanía».

De ahí que haya que saludar la publicación de El derecho a la educación en España. Bases constitucionales para el acuerdo y cuestiones controvertidas, del profesor Carlos Vidal Prado, en la nueva colección sobre «Debates constitucionales» de la Fundación Manuel Giménez Abad y la Editorial Marcial Pons. Si con esta colección ambas instituciones pretenden convertirse en una «modesta pero rigurosa aportación al debate político y jurídico existente alrededor de los temas de mayor actualidad», en el título que comentamos se cumple con creces el propósito.

En apretadas 150 páginas (la extensión propia de esta colección), se abordan las cuestiones más relevantes sobre el derecho a la educación en nuestro país, con equilibrio y ponderación, no tan frecuentes en una cuestión tan sensible como la educación y la enseñanza.

El libro se divide en 8 capítulos. Los tres primeros ofrecen un repaso por el marco constitucional de los derechos educativos, así como la normativa de desarrollo de las previsiones constitucionales, que ha sufrido notables modificaciones en estos casi cuarenta años de vigencia de la Constitución. Sin 
embargo, el autor subraya que los rasgos fundamentales del sistema educativo no han sido modificados desde los años ochenta, en los que la LODE y, sobre todo, la LOGSE, fijaron las bases que hoy todavía permanecen vigentes. Por otro lado, también matiza la idea de que cada vez que hay cambio del color político del Gobierno, se elabora una nueva Ley. En realidad, como se explica en el volumen, las leyes educativas principales han sido aprobadas por gobiernos socialistas, mientras que los de centro derecha solamente han aprobado dos: la LOECE (muy sectorial, sobre el estatuto de los centros) y la LOMCE (que, en realidad, es una modificación de la LOE aprobada por el Gobierno Zapatero).

En los capítulos IV y V se analizan las distintas dimensiones del derecho a la educación, exponiendo las diferentes posiciones doctrinales y jurisprudenciales sobre esta cuestión. Resulta especialmente interesante el estudio que se lleva a cabo en el capítulo $\mathrm{V}$ de la relevancia que tiene el respeto a los valores constitucionales en el ámbito educativo, y si puede hablarse o no de un «ideario educativo constitucional». Como deja entrever el autor en este capítulo y, sobre todo, en el último (de «Valoraciones finales»), no parece que pueda hablarse de un ideario constitucional para la educación, sino en todo caso de una serie de valores que deben ser respetados, pero sin que parezca que pueda llegarse a un cierto adoctrinamiento, como sin embargo sí defienden otras posiciones doctrinales en España.

Ese respeto a los valores constitucionales debe garantizarse en todos los centros, incluyendo por supuesto aquellos que tienen ideario o carácter propio, cuyo contenido debe moverse dentro de los límites que la propia Constitución determina. También se analiza la necesidad de una materia como Educación para la Ciudadanía, ya sea contemplada como asignatura específica, ya como contenidos transversales incluidos en distintas asignaturas. El autor analiza críticamente la jurisprudencia de los tribunales ordinarios y del Tribunal Supremo sobre esta cuestión. Por último, también se aborda el problema de la educación diferenciada, inclinándose Vidal Prado por sostener que se trataría de una opción pedagógica o metodológica, que entraría dentro del ámbito del carácter propio de cada centro.

Algunas características del Derecho a la educación como derecho de libertad se estudian en el capítulo VI, como por ejemplo los posibles conflictos entre la libertad de cátedra del docente y el ideario del centro en el que desarrolla su labor educativa. Tanto en este capítulo como en el resto, la atención del autor se centra sobre todo en la educación no universitaria, pero va realizando algunos apuntes también referidos al ámbito universitario, como por ejemplo a la autonomía de las Universidades garantizada en el art. 27.10 de la Constitución.

En el capítulo VII se analiza una cuestión crítica en estos últimos años de crisis económica, como es la financiación de la educación, tanto en lo que se refiere al gasto público educativo en general, como a cuestiones concretas como la de la financiación destinada a las becas y ayudas al estudio. Con datos oficiales, se puede constatar la evolución de ese gasto estatal 
(que, en realidad, como bien se apunta, es una inversión), que evidentemente se ha reducido en los años más duros de la crisis, aunque se ha comenzado a recuperar, sobre todo a partir de 2015. Asimismo, se analiza con detalle la financiación de las becas, explicando por qué es verdad tanto lo que dice el Gobierno (el gasto presupuestado en becas es el más alto de la historia) como la oposición (el gasto ejecutado en becas y ayudas al estudio ha disminuido unos años, hasta que se ha empezado a recuperar de nuevo a partir de 2015).

Finalmente, en el último capítulo se incluyen unas valoraciones finales, en las que el autor expone con más detenimiento su opinión en algunas de las cuestiones controvertidas que ha ido repasando a lo largo del texto, en el que, como se ha dicho, se procura mantener un equilibrio al exponer cuáles son las posiciones de unos y otros en cada materia controvertida.

Vidal Prado reivindica el valor del consenso constitucional en el ámbito de los derechos educativos, y defiende que los trabajos para poder alcanzar un (necesario) Pacto educativo deberían tener muy presente la senda que nos marcaron los constituyentes. En este sentido, el artículo 27 de la Constitución ofrece un buen sustrato para poder construir, a partir de él, ese acuerdo entre todas las fuerzas políticas, o al menos la mayoría de ellas.

En consecuencia, estamos ante una oportuna aportación, de un autor que ya había efectuado numerosas contribuciones doctrinales sobre los derechos educativos, que llega en un momento muy propicio para que se tengan en cuenta sus ideas en la configuración del Pacto por la educación en España.

Pablo Nuevo López

Profesor de Derecho constitucional Universidad Abat Oliba CEU. 